\title{
Article
}

\section{The effects of Ankle Protectors on Lower Limb Kinematics in male football players: A comparison to Braced and Unbraced Ankles}

Graydon, Robert William, Fewtrell, David John, Atkins, Stephen and Sinclair, Jonathan Kenneth

Available at http://clok.uclan.ac.uk/17482/

Graydon, Robert William ORCID: 0000-0002-8704-5126, Fewtrell, David John ORCID: 0000-0002-9015-1413, Atkins, Stephen and Sinclair, Jonathan Kenneth ORCID: 0000-0002-2231-3732 (2017) The effects of Ankle Protectors on Lower Limb Kinematics in male football players: A comparison to Braced and Unbraced Ankles. Comparative Exercise Physiology, 13 (4). pp. 251-258. ISSN $1755-2540$

It is advisable to refer to the publisher's version if you intend to cite from the work. http://dx.doi.org/10.3920/CEP160031

For more information about UCLan's research in this area go to http://www.uclan.ac.uk/researchgroups/ and search for < name of research Group>.

For information about Research generally at UCLan please go to http://www.uclan.ac.uk/research/

All outputs in CLoK are protected by Intellectual Property Rights law, including Copyright law. Copyright, IPR and Moral Rights for the works on this site are retained by the individual authors and/or other copyright owners. Terms and conditions for use of this material are defined in the policies page. 


\section{Comparative Exercise Physiology}

\section{The effects of Ankle Protectors on Lower Limb Kinematics in male football players. A comparison to Braced and Unbraced Ankles. \\ --Manuscript Draft--}

\begin{tabular}{|c|c|}
\hline Manuscript Number: & CEP-160031R2 \\
\hline Full Title: & $\begin{array}{l}\text { The effects of Ankle Protectors on Lower Limb Kinematics in male football players. A } \\
\text { comparison to Braced and Unbraced Ankles. }\end{array}$ \\
\hline Corresponding Author: & $\begin{array}{l}\text { Robert Graydon } \\
\text { Preston, UNITED KINGDOM }\end{array}$ \\
\hline \multicolumn{2}{|c|}{$\begin{array}{l}\text { Corresponding Author Secondary } \\
\text { Information: }\end{array}$} \\
\hline \multicolumn{2}{|c|}{ Corresponding Author's Institution: } \\
\hline \multicolumn{2}{|c|}{$\begin{array}{l}\text { Corresponding Author's Secondary } \\
\text { Institution: }\end{array}$} \\
\hline \multirow[t]{4}{*}{ Order of Authors: } & Robert Graydon \\
\hline & David Fewtrell \\
\hline & Stephen Atkins \\
\hline & Jonathan Sinclair \\
\hline \multicolumn{2}{|c|}{ Order of Authors Secondary Information: } \\
\hline Abstract: & $\begin{array}{l}\text { Football (Soccer) players have a high risk of injuring the lower extremities. To reduce } \\
\text { the risk of ankle inversion injuries ankle braces can be worn. To reduce the risk of } \\
\text { ankle contusion injuries ankle protectors can be utilized. However, athletes can only } \\
\text { wear one of these devices at a time. The effects of ankle braces on stance limb } \\
\text { kinematics has been extensively researched, however ankle protectors have had little } \\
\text { attention. Therefore, the current study aimed to investigate the effects of ankle } \\
\text { protectors on lower extremity kinematics during the stance phase of jogging and } \\
\text { compare them with braced and uncovered ankles. Twelve male participants ran at } 3.4 \\
\text { m.s-1 in three test conditions; ankle braces (BRACE), ankle protectors (PROTECTOR) } \\
\text { and with uncovered ankles (WITHOUT). Stance phase kinematics were collected using } \\
\text { an eight-camera motion capture system. Kinematic data between conditions were } \\
\text { analysed using one-way repeated measures ANOVA. The results showed that BRACE } \\
\left(\text { absolute range of motion }(R O M)=10.72^{\circ} \& \text { relative ROM }=10.26^{\circ}\right) \text { significantly } \\
(P<0.05) \text { restricted the ankle in the coronal plane when compared to PROTECTOR } \\
\left(\text { absolute ROM }=13.44^{\circ} \& \text { relative ROM }=12.82^{\circ}\right) \text { and WITHOUT (absolute ROM } \\
\left.=13.64^{\circ} \& \text { relative ROM }=13.10^{\circ}\right) \text {. It was also found that both BRACE (peak } \\
\text { dorsiflexion }=17.02^{\circ} \& \text { absolute ROM }=38.34^{\circ} \text { ) and PROTECTOR (peak dorsiflexion } \\
\left.=18.46^{\circ} \& \text { absolute ROM }=40.15^{\circ}\right) \text { significantly }(P<0.05) \text { reduced sagittal plane motion } \\
\text { when compared to WITHOUT (peak dorsiflexion }=19.20^{\circ} \& \text { absolute ROM }=42.66^{\circ} \text { ). } \\
\text { Ankle protectors' effects on lower limb kinematics closely resemble that of an unbraced } \\
\text { ankle. Therefore, ankle protectors should only be used as a means to reduce risk of } \\
\text { ankle contusion injuries and not implemented as a method to reduce the risk of ankle } \\
\text { inversion injuries. Furthermore, the reductions found in sagittal plane motion of the } \\
\text { ankle could possibly increase the bodies energy demand needed for locomotion when } \\
\text { ankle protectors are utilised. }\end{array}$ \\
\hline
\end{tabular}


1 The effects of Ankle Protectors on lower limb kinematics in male football players. A

2

3

4

5

6

7

8 Corresponding author contact details:

9 Robert Graydon

10 Centre for Applied Sport \& Exercise Sciences

11 University of Central Lancashire

12 Preston

13 Lancashire

14 PR1 2HE

15 E-mail: $\underline{\text { RWGraydon@ uclan.ac.uk }}$

$16 \quad$ Funding Declaration

17 No external funding was provided.

18

\section{Conflict of Interest Declaration}

19 No conflict of interest.
University of Central Lancashire, UK

2. School of Health Sciences, University of Salford, UK 
21 Keywords: Biomechanics, motion analysis, Ankle Braces, Ankle Protectors, Football,

22

23

Soccer.

\section{Abstract}

Football (Soccer) players have a high risk of injuring the lower extremities. To reduce the risk of ankle inversion injuries ankle braces can be worn. To reduce the risk of ankle contusion injuries ankle protectors can be utilized. However, athletes can only wear one of these devices at a time. The effects of ankle braces on stance limb kinematics has been extensively researched, however ankle protectors have had little attention. Therefore, the current study aimed to investigate the effects of ankle protectors on lower extremity kinematics during the stance phase of jogging and compare them with braced and uncovered ankles. Twelve male participants ran at $3.4 \mathrm{~m} . \mathrm{s}^{-1}$ in three test conditions; ankle braces (BRACE), ankle protectors (PROTECTOR) and with uncovered ankles (WITHOUT). Stance phase kinematics were collected using an eight-camera motion capture system. Kinematic data between conditions were analysed using one-way repeated measures ANOVA. The results showed that BRACE (absolute range of motion $(\mathrm{ROM})=10.72^{\circ} \&$ relative $\left.\mathrm{ROM}=10.26^{\circ}\right)$ significantly $(\mathrm{P}<0.05)$ restricted the ankle in the coronal plane when compared to PROTECTOR (absolute ROM $=13.44^{\circ} \&$ relative $\left.\mathrm{ROM}=12.82^{\circ}\right)$ and WITHOUT $\left(\right.$ absolute $\mathrm{ROM}=13.64^{\circ} \&$ relative $\mathrm{ROM}$ $=13.10^{\circ}$ ). It was also found that both BRACE (peak dorsiflexion $=17.02^{\circ} \&$ absolute ROM $=38.34^{\circ}$ ) and PROTECTOR (peak dorsiflexion $=18.46^{\circ} \&$ absolute $\mathrm{ROM}=40.15^{\circ}$ ) significantly $(\mathrm{P}<0.05)$ reduced sagittal plane motion when compared to WITHOUT (peak dorsiflexion $=19.20^{\circ} \&$ absolute $\mathrm{ROM}=42.66^{\circ}$ ). Ankle protectors' effects on lower limb kinematics closely resemble that of an unbraced ankle. Therefore, ankle protectors should only be used as a means to reduce risk of ankle contusion injuries and not implemented as a method to reduce the risk of ankle inversion injuries. Furthermore, the reductions found in sagittal plane 
motion of the ankle could possibly increase the bodies energy demand needed for locomotion when ankle protectors are utilised.

\section{Introduction}

Football (Soccer) is an immensely popular sport with an estimated 265 million participants worldwide (FIFA Communications Division, 2007). Unfortunately, as with any sport, there is an inherent risk of injury to participants and football is no exception. Figures for injury incidences vary among studies due to differing methodologies, time frames observed, ability of participants and competitions observed but conclude there are approximately 25 to 43.53 injuries per 1000 hours of competitive match play (Andersen, et al., 2004; Hägglund, et al., 2013; Hawkins \& Fuller, 1999; Salces, et al., 2014). Losing an integral team member can lead to a reduced chance of winning competitive matches and further more lead to loss of major trophies (Hägglund, et al., 2013). Therefore, an understanding of the common types of injury sustained by players and also methods to reduce the occurrence of injury is a high priority for football clubs.

Footballing injuries mainly occur to the lower extremities (Ekstrand, et al., 2011) with the ankle being one of the most commonly injured sites amongst players (Junge \& Dvorak, 2013). Ankle inversion injuries and contusion injuries account for a large proportion of the total amount of ankle injuries (Waldén, et al., 2013). Once a player has suffered an ankle inversion injury they have an increased risk of reinjuring the ankle (Thacker, et al., 1999). To reduce the risk of ankle inversion injuries ankle braces can be worn (Kaplan, 2011), the ankles can be taped (Verhagen, et al., 2000), or a neuromuscular training program can be utilised (McGuine \& Keene, 2006). Using tape to support the ankle has been found to be ineffective after approximately fifteen 
minutes of use (Lohkamp, et al., 2009) and expensive (Olmsted, et al., 2004), whereas neuromuscular training programs have been found to be effective but take long periods of time to implement (Emery \& Meeuwisse, 2010). This makes ankle braces an attractive alternative because they are easy to put on, do not need to be regularly replaced, and have been found to reduce the risk of ankle inversion injury by restricting the range of motion of the ankle (Farwell, et al., 2013; Janssen, et al., 2014; Pedowitz, et al., 2008). To reduce the risk of contusion injuries ankle protectors can be worn which utilise foam constructs to reduce forces being transferred to the ankle (Ankrah \& Mills, 2002; Ankrah \& Mills, 2004). Unfortunately, due to ankle braces and ankle protectors aiming to reduce differing injuries at the same location only one of these devices can be used at any one time. This selection is dependent on whether the wearer wants to reduce the risk of acute or chronic injuries.

Ankle braces effects on ankle kinematics have been well established and have been found to reduce the amount of movement of the ankle (Tang, et al., 2010; DiStefano, et al., 2008) whilst having little effect on running performance (Locke, et al., 1997; Gross, et al., 1997; Bocchinfuso, et al., 1994). The effects of ankle braces on knee and hip kinematics has also been previously studied and found to, in some sporting tasks, increase knee axial rotation which could indicate a higher risk of knee injury (Santos, et al., 2004). However, the effects of ankle protectors' on ankle kinematics during running has, to the author's best knowledge, had no attention. As the location of ankle protectors are the same as ankle braces there is a possibility that they inadvertently act like ankle braces by reducing the amount of movement of the ankle whilst running. If ankle protectors are found to produce similar ankle kinematics to braced ankles, health care professionals could potentially recommend ankle protectors to reduce the risk of both ankle inversion injuries and ankle contusion injuries. Therefore, the current study aims to investigate; firstly, the effects of ankle protectors on ankle kinematics during the stance phase of a wearers running gait, secondly, compare the effects of ankle protectors on ankle 
94 kinematics with braced and unbraced ankles to establish which it more closely resembles, and thirdly, investigate the effects of ankle protectors on knee and hip kinematics.

96

97

Method

98

Participants

99

Twelve male participants took part in this study. Participants were recruited from local and university football teams using poster adverts. The inclusion criteria for the study was that the participant were aged between 18 and 35, currently playing for a football team, and were injury free at the time of testing. All participants provided written consent in line with the University of Central Lancashire's ethical panel (STEMH 309).

\section{Ankle Braces and Ankle Protectors}

The ankle protectors used for the current investigation were a pair of Nike ankle shield 10 (Nike Inc, Washington County, Oregon, USA) and the ankle braces used were a pair of Aircast A60 (DJO, Vista, CA, USA).

\section{Procedure}

113 Participants performed running trials across a $22 \mathrm{~m}$ biomechanics laboratory in three test 114 conditions; wearing ankle braces (BRACE), wearing ankle protectors (PROTECTOR) and 115 with uncovered ankles (WITHOUT). Five successful trials were recorded for each test 
condition. A successful trial was determined as one in which the participant landed with the

117 whole of their right foot on an embedded force platform (Kistler Instruments Ltd., Alton, Hampshire) located in the centre of the laboratory, did not focus on the force plate as to alter their natural gait pattern (Sinclair, et al., 2014), and kept within a speed tolerance of $3.4 \mathrm{~m} . \mathrm{s}^{-1}$ $\pm 5 \%$. The force plate sampled at $1000 \mathrm{~Hz}$ and was used to determine the start and end of the stance phase during the running trials. These points were determined as the point where the force plate first recorded a vertical ground reaction force (VGRF) that exceeded $20 \mathrm{~N}$ and ended when the VGRF dropped back down below 20N (Sinclair, et al., 2011).

Kinematic data were recorded using an eight camera motion capture system (Qualisys Medical $\mathrm{AB}$, Goteburg, Sweden) tracking retro-reflective markers at a sampling rate of $250 \mathrm{~Hz}$. Using the calibrated anatomical system technique (CAST) (Cappozzo, et al., 1995) the retro-reflective markers were attached to the 1st and 5th metatarsal heads, calcaneus, medial and lateral malleoli, the medial and lateral femoral epicondyles, the greater trochanter, Left and right anterior superior iliac spine, and left and right posterior superior iliac spine. These markers were used to model the right foot, shank, thigh, and pelvis segments in six degrees of freedom. Rigid plastic mounts with four markers on each were also attached to the shank and thigh and and to track the pelvis the left and right anterior superior iliac spine and left and right posterior superior iliac spine were used. In the BRACE condition the medial and lateral malleoli locations were found by placing the index finger under the rigid construct of the brace to locate the anatomical landmark then matching the location to the exterior of the Brace where the marker was then fixed to. In the PROTECTOR condition the medial and lateral malleoli locations were located by palpating the soft foam construct to find the underlying anatomical 
landmarks. To assess the speed of the participant a single marker was attached to the xiphoid process and was checked for velocity using the QTM software after each trial was recorded. Before dynamic trials were captured a static trial of the participant stood in the anatomical position was captured which was used to identify the location of the tracking makers with reference to the anatomical markers. To define each plane of motion firstly the $\mathrm{Z}$ (transverse) axis follows the segment from distal to proximal and denotes internal/external rotation, secondly the $\mathrm{Y}$ (coronal) axis is orientated from anterior to posterior of the segment and denotes adduction/abduction, and thirdly the $\mathrm{X}$ (sagittal) axis is orientated from medial to lateral of the segment and denotes flexion/extension.

Data Processing

152 Anatomical and tracking markers were identified within the Qualisys Track Manager software and then exported as C3D files to be analysed using Visual 3-D software (C-Motion, Germantown, MD, USA). To define the centre points of the ankle and knee segments the two marker methods were utilised for both. These methods calculate the centre of the joint using the positioning of the malleoli markers for the ankle centre and the femoral epicondyle markers for the knee centre (Graydon, et al., 2015; Sinclair, et al., 2015). To calculate the hip joint centre a regression equation which uses the position of the ASIS markers was utilised (Sinclair, et al., 2014). The running trials were filtered at $12 \mathrm{~Hz}$ using a low pass 4 th order zero-lag filter Butterworth filter. Data were normalized to $100 \%$ of the stance phase then processed trials were used to produce means of the five trials for each test condition for each participant. 3D kinematics of the ankle, knee and hip joints of the right leg were calculated using an XYZ cardan sequence of rotations. The 3D joint kinematic measures which were extracted for further analysis were 1) angle at footstrike, 2) angle at toe-off, 3) peak angle during the stance phase, 
4) Absolute range of motion (Absolute ROM) calculated by taking the maximum angle from the minimum angle during stance, 5), Relative range of motion (Relative ROM) calculated using the angle at footstrike and the first peak value after footstrike.

Statistical analyses

Data analysis was conducted using SPSS v22.0 (SPSS Inc., Chicago, IL, USA). The means of the five trials for each of the three test conditions were compared using one-way repeated measures ANOVA with significant findings, accepted at $\mathrm{P}<0.05$ level, being further explored using post-hoc pairwise comparisons. Effect sizes were determined using partial $\operatorname{Eta}^{2}\left(\eta^{2}\right)$.

\section{Results}

The demographic of the participants of the current study were; age $24.8 \pm 4.8$ years, height $174.8 \pm 5.8 \mathrm{~cm}$, body mass $73.4 \pm 10.5 \mathrm{~kg}$ and BMI $24.0 \pm 2.7$. and 3 display the 3D kinematic waveforms recorded for each condition in each plane of motion.

For the ankle joint, in the Sagittal plane, significant main effects were found for the Angle at footstrike $\mathrm{F}_{(2,22)}=5.04, \mathrm{P}<0.05, \eta^{2}=0.31$, Angle at toe-off $\mathrm{F}_{(2,22)}=11.95, \mathrm{P}<0.05, \eta^{2}=0.52$, Peak dorsiflexion angle $\mathrm{F}_{(2,22)}=23.27, \mathrm{P}<0.05, \eta^{2}=0.68$, and Absolute $\operatorname{ROM} \mathrm{F}_{(2,22)}=31.12$, $\mathrm{P}<0.05, \eta^{2}=0.74$. Post-hoc analysis revealed that the BRACE condition exhibited significantly 
$187(\mathrm{P}<0.05)$ lower angle at footstrike than the PROTECTOR condition. It also revealed the BRACE and PROTECTOR conditions had a significant $(\mathrm{P}<0.05)$ reduction in angle at toe off than the WITHOUT condition. The BRACE condition significantly $(\mathrm{P}<0.05)$ reduced peak dorsiflexion when compared to the other groups and all three conditions were significantly $(\mathrm{P}<0.05)$ different from each other for Absolute range of motion with the WITHOUT condition having the most ROM and BRACE condition having the least ROM.

For the ankle joint, in the coronal plane, significant main effects were found for the Angle at footstrike $\mathrm{F}_{(2,22)}=7.34, \mathrm{P}<0.05, \eta^{2}=0.40$, Angle at toe-off $\mathrm{F}_{(2,22)}=6.02, \mathrm{P}<0.05, \eta^{2}=0.35$, Peak Inversion angle $\mathrm{F}_{(2,22)}=10.22, \mathrm{P}<0.05, \eta^{2}=0.48$, Peak Eversion angle $\mathrm{F}_{(1.19,13.14)}=6.80$, $\mathrm{P}<0.05, \eta^{2}=0.38$, Relative ROM F $(2,22)=18.40, \mathrm{P}<0.05, \eta^{2}=0.63$, and Absolute ROM F $(2,22)$ $=25.19, \mathrm{P}<0.05, \eta^{2}=0.70$. Post-hoc analysis revealed that the BRACE condition significantly $(\mathrm{P}<0.05)$ reduced angle at footstrike, angle at toe off, and peak inversion angle when compared with the WITHOUT condition. The BRACE condition also exhibited significantly $(\mathrm{P}<0.05)$ lower peak eversion angle when compared to the PROTECTOR condition. It was also revealed that the BRACE condition had significantly $(\mathrm{P}<0.05)$ lower Absolute and Relative ROM's when compared to both the WITHOUT and PROTECTOR conditions. of the planes of motion for both the knee joint and the hip joint. 


\section{Discussion}

211 The aim of the current study was to investigate the effects of ankle protectors on ankle

212 kinematics during the stance phase of a wearers running gait, compare the effects of ankle 213 protectors with braced and unbraced ankles to establish which it more closely resembles, and investigate the effects of ankle protectors on knee and hip kinematics.

Previous research reviewing the effectiveness of ankle braces has found them to reduce the risk of inversion injury (Farwell, et al., 2013) and it is a reduction in coronal plane kinematics which is likely the main contributor to the reduction in risk of inversion injuries (Tang, et al., 2010). Ankle protectors aim to reduce contusion injuries and have previously been found to be effective at this (Ankrah \& Mills, 2004). However, it was previously unknown whether an ankle protector inadvertently restricts the ankle, due to its location, which may cause restrictions similar to ankle braces. It is evident from the results from the current study that ankle protectors do not significantly restrict the ankle in the coronal plane and replicate similar movement to that of an ankle free of orthotic support. The lack of restriction is due to the soft foam construct of the ankle protector which is far less rigid than the plastic polymer contained against ankle inversion injuries like ankle braces.

The sagittal plane results produced some interesting observations. The angle at toe off was significantly reduced in the BRACED \& PROTECTOR conditions when compared to the WITHOUT condition. Also Absolute ROM was reduced in these conditions too, these results suggest that there is an impedance on the ankle when wearing an ankle protector. The reduction 
in movement in this plane might be due to the way both the ankle braces and ankle protectors sit on the ankle. The ankle braces have a support strap that runs around the front and rear of the ankle which allows the brace to be tightened. The tightening of this strap is likely to reduce the movement of the ankle by restricting the ankle in the sagittal plane. As for the ankle protector, although the soft foam is designed not to come all the way over the front of the foot, on many of the participants the foam did encroach on the front of the foot due to its "one size fits all" design. The location of the foam at the front of the ankle joint could possibly explain the reduction of sagittal plane movement when wearing the ankle protector. Reductions in ankle motion in the sagittal plane have been shown to increase energy expenditure (Huang, et al., 2015). The reductions in ankle ROM seen in the current study could suggest that ankle protectors could cause earlier onset of fatigue for a wearer during prolong use such as during competitive match play. This is beyond the scope of the current study but should be investigated further.

Although no restrictions of the ankle in the coronal plane were observed for the ankle protectors there is a possibility they might provide proprioceptive cues to the wearer, which may be beneficial to reduce the overall risk of inversion injury. This has been seen with ankle taping where the effectiveness of the tape does not exceed more than approximately fifteen minutes of use (Lohkamp, et al., 2009) but has been found to significantly reduce the risk of ankle injury when compared to not wearing any tape (Verhagen, et al., 2000). Again this is beyond the scope of the current investigation but one that should be researched in the future to compare inversion injury rates of players wearing ankle protectors' verses players who do not wear ankle protectors. 
Previous research has shown some ankle devices alter knee and hip kinematics which could increase the likelihood of sustaining an injury higher up the kinematic chain (Santos, et al., 2004). Looking at the results of the current study it can be seen that the knee and hip kinematics were found to not be significantly different between the test conditions. The implementation of the ankle braces and ankle protectors used in the current study do not increase the risk of injuring the knee or hip by altering the kinematics of these locations.

The current study has limited applicability due to the relatively comfortable jogging pace the participants ran at and further research is required to investigate the effects of ankle protectors during nonlinear motion, during jumping, during kicking a football, and also how they affect female footballers. Furthermore, some of the kinematic data show large standard deviations. These large deviations may be due to differing running styles exhibited by the participants, and in some cases such as the hip, due to the movement of the tightly fitted sports shorts worn by participants. Also although markers affixed to the malleoli were not used to track the dynamic movement there is still a possibility that error in their application may cause errors within the data collected as they were used for defining segments in the static model.

The current study has established that ankle protectors provide very little restriction to the ankle when jogging and do not restrict the ankle like ankle braces. Therefore, ankle protectors should only be used as a means to reduce risk of ankle contusion injuries and not implemented as a method to reduce the risk of ankle inversion injuries. It must be noted that although no restrictions were seen in the coronal plane there were reductions in sagittal plane motion for the ankle which could possibly increase energy demand needed for locomotion. 


\section{References}

282

283

284

Ambegaonkar, J. P. et al., 2011. Ankle stabilizers affect agility but not vertical jump or dynamic balance performance.. Foot \& Ankle Specialist, 4(6), pp. 354-360.

Andersen, T. E., Floerenes, T. W., Arnason, A. \& Bahr, R., 2004. Video Analysis of the Mechanisms for Ankle Injuries in Football. The American Journal of Sports Medicine, 32(1), pp. 69-79.

Ankrah, S. \& Mills, N., 2002. Ankle Protection in Football Shin Guards. The Engineering of Sport, pp. 128-135.

Ankrah, S. \& Mills, N., 2004. Analysis of ankle protection in Association football.. Sports Engineering, 7(1), pp. 41-52.

Bocchinfuso, C., Sitler, M. R. \& Kimur, I. F., 1994. Effects of two semi-rigid prophylactic ankle stabilizers on speed, agility, and vertical jump. Journal of Sport Rehabilitation, 3(2), pp. $125-134$

Burks, R. T., Bean, B. G., Marcus, R. \& Barker, H. B., 1991. Analysis of athletic performance with prophylactic ankle devices. The American Journal of Sports Medicine, 19(2), pp. 104106.

Cappozzo, A., Catani, F., Croce, U. D. \& Leardini, A., 1995. Position and orientation in space of bones during movement: anatomical frame definition and determination.. Clin Biomech, 10(4), pp. 171-178.

DiStefano, L. J., Padua, D. A., Brown, C. N. \& Guskiewicz, K. M., 2008. Lower Extremity Kinematics and Ground Reaction Forces After Prophylactic Lace-Up Ankle Bracing. Journal of Athletic Training, 43(3), pp. 234-241. 
Ekstrand, J., Hägglund, M. \& Waldén, M., 2011. Injury incidence and injury patterns in professional football: the UEFA injury study. British Journal of Sports Medicine, Volume 45, pp. 553-558.

Emery, C. A. \& Meeuwisse, W. H., 2010. The effectiveness of a neuromuscular prevention strategy to reduce injuries in youth soccer: a cluster-randomised controlled trial. British Journal of Sports Medicine, 44(8), pp. 555-562.

Farwell, K. E. et al., 2013. The Effectiveness of Prophylactic Ankle Braces in Reducing the Incidence of Acute Ankle Injuries in Adolescent Athletes: A Critically Appraised Topic. Journal of Sport Rehabilitation, Volume 22, pp. 137-142.

Division,

2007.

[Online]

313 Available at:

314 http://www.fifa.com/mm/document/fifafacts/bcoffsurv/bigcount.statspackage 7024.pdf

$315 \quad$ [Accessed 2001 2017].

Graydon, R., Fewtrell, D., Atkins, S. \& Sinclair, J., 2015. The test-retest reliability of different ankle joint center location techniques. The Foot and Ankle Online Journal, 8(1), p. 11.

Gross, M. T. et al., 1997. Effect of ankle orthoses on functional performance for individuals with recurrent lateral ankle sprains.. J Orthop Sports Phys Ther., 25(4), pp. 245-252.

Hägglund, M. et al., 2013. Injuries affect team performance negatively in professional football: an 11-year follow-up of the UEFA Champions League injury study. British Journal of Sports Medicine, Volume 47, pp. 738-742. English professional football clubs. British Journal Of Sports Medicine, 33(3), pp. 196-203. 
Huang, T. P., Shorter, K. A., Adamczyk, P. G. \& Kuo, A. D., 2015. Mechanical and energetic consequences of reduced ankle plantar-flexion in human walking. Journal of Experimental Biology, Volume 218, pp. 3541-3550.

Janssen, K. W., Mechelen, W. V. \& Verhagen, E. A. L. M., 2014. Bracing superior to neuromuscular training for the prevention of self-reported recurrent ankle sprains: a three-arm randomised controlled trial. British Journal of Sports Medicine, Volume 48, pp. 1235-1239.

Jones, D., Rawnsley, P. \& Switzer, A., 2014. Deloitte. [Online]

Available at: http://www2.deloitte.com/content/dam/Deloitte/uk/Documents/sports-businessgroup/deloitte-uk-annual-review-football-finance.pdf

[Accessed 2803 2015].

Junge, A. \& Dvorak, J., 2013. Injury surveillance in the World Football Tournaments 1998 2012. British Journal of Sports Medicine, Volume 47, pp. 782-788.

Kaplan, Y., 2011. Prevention of ankle sprains in sport: a systematic literature review. British Journal Of Sports Medicine, 45(4), p. 355.

Locke, A., Sitler, M., Aland, C. \& Kimura, I., 1997. Long-Term use of a Softshell Prophylactic

Ankle Stabilizer on speed, agility, and vertical jump performance. Journal of Sport Rehabilitation, Volume 6, pp. 235-245.

Lohkamp, M., Craven, S., Walker-Johnson, C. \& Greig, M., 2009. The Influence of Ankle

Taping on Changes in Postural Stability During Soccer-Specific Activity. Journal of Sport Rehabilitation, Volume 18, pp. 482-492. effects on functional performance in female basketball players. J Orthop Sports Phys Ther, 22(2), pp. 77-81. 
McGuine, T. A. \& Keene, J. S., 2006. The Effect of a Balance Training Program on the Risk of Ankle Sprains in High School Athletes. The American Journal of Sports Medicine, 34(7), pp. 1103-1111.

Olmsted, L. C., Vela, L. I., Denegar, C. R. \& Hertel, J., 2004. Prophylactic Ankle Taping and Bracing: A Numbers-Needed-to-Treat and Cost-Benefit Analysis. Journal of Athletic Training, 39(1), pp. 95-100.

Pedowitz, D. I. et al., 2008. Prophylactic Bracing Decreases Ankle Injuries in Collegiate Female Volleyball Players. The American Journal of Sports Medicine, 36(2), pp. 324-327.

Salces, J. N. et al., 2014. Epidemiology of injuries in First Division Spanish Football. Journal of Sports Sciences, 32(13), pp. 1263-1270.

Santos, M. J., McIntire, K., Foecking, J. \& Liu, W., 2004. The effects of ankle bracing on motion of the knee and hip joint during trunk roatation tasks.. Clinical Biomechanics, 19(9), pp. 964-971.

Sinclair, J., Edmundson, C. J., Brooks, D. \& Hobbs, S. J., 2011. Evaluation of kinematic methods of identifying gait events during running. Int J Sp Sci Eng, Volume 5, pp. 188-192.

Sinclair, J., Hebron, J. \& Taylor, P. J., 2015. The test-retest reliability of knee joint center location techniques.. Journal of Applied Biomechanics, Volume 31, pp. 117-121.

Sinclair, J. et al., 2014. The Influence of Different Force and Pressure Measuring Transducers on Lower Extremity Kinematics Measured During Running. Journal of applied biomechanics, 30(1), pp. 166-172.

Sinclair, J., Taylor, P. J., Currigan, G. \& Hobbs, S. J., 2014. The test-retest reliability of three different hip joint centre location techniques.. Movement \& Sport Sciences, Volume 83, pp. 3139. 
371 Tang, Y. M., Wu, Z. H., Liao, W. H. \& Chan, K. M., 2010. A study of semi-rigid support on ankle supination sprain kinematics. Scandinavian Journal of Medicine \& Science in Sports, Volume 20, pp. 822-826.

Thacker, S. B. et al., 1999. The Prevention of Ankle Sprains in Sports. The American Journal of Sports Medicine, 27(6), pp. 753-760.

Verhagen, E. A. L. M., van Mechelen, W. \& de Vente, W., 2000. The Effect of Preventive Measures on the Incidence of Ankle Sprains. Clinical Journal of Sport Medicine, 10(4), pp. 291-296.

Waldén, M., Hägglund, M. \& Ekstrand, J., 2013. Time-trends and circumstances surrounding ankle injuries in men's professional football: an 11-year follow-up of the UEFA Champions League injury study. British Journal of Sports Medicine, Volume 47, pp. 748-753.

Yaggie, J. A. \& Kinzey, S. J., 2001. A comparative analysis of selected ankle orthoses during functional tasks. Journal of Sport Rehabilitation, 10(3), pp. 174-183.

\section{List of figures}

Figure 1. On the left a pair of Nike ankle shield 10 ankle protectors and on the right an Aircast A60 ankle brace.

Figure 2. Ankle joint kinematics during the stance phase of locomotion a. sagittal, b. coronal and c. transverse planes $(\mathrm{PROTECTOR}=$ black, $\mathrm{BRACE}=$ grey, WITHOUT $=$ dash $)(\mathrm{DF}=$ dorsiflexion, $\mathrm{IN}=$ inversion, $\mathrm{EXT}=$ external rotation).

Figure 3. Knee joint kinematics during the stance phase of locomotion a. sagittal, b. coronal and c. transverse planes $(\mathrm{PROTECTOR}=$ black, $\mathrm{BRACE}=$ grey, WITHOUT $=$ dash $)(\mathrm{FL}=$ flexion, $\mathrm{AD}=$ adduction, $\mathrm{INT}=$ internal rotation). 
Figure 4. Hip joint kinematics during the stance phase of locomotion a. sagittal, b. coronal and

$396 \mathrm{AD}=$ adduction, $\mathrm{INT}=$ internal rotation $).$

397 Tables

398 Table 1. Kinematic data (means and stand deviations) for the ankle obtained during stance

399 phase of the running gait.

\begin{tabular}{|c|c|c|c|c|c|}
\hline \multirow{2}{*}{$\begin{array}{c}\text { Sagittal plane }(+=\text { dorsiflexion } /-= \\
\text { plantarflexion })\end{array}$} & \multirow[t]{2}{*}{ WITHOUT } & \multicolumn{2}{|c|}{ PROTECTOR } & \multicolumn{2}{|l|}{ BRACE } \\
\hline & & & & & \\
\hline Angle at footstrike $\left(^{\circ}\right)$ & $6.20 \pm 7.42$ & $6.05 \pm 6.82$ & & $4.15 \pm 5.64$ & $\mathrm{~B}$ \\
\hline Angle at toe-off $\left(^{\circ}\right)$ & $-23.65 \pm 4.13$ & $-21.69 \pm 3.85$ & A & $-21.32 \pm 3.22$ & A \\
\hline Peak dorsiflexion $\left(^{\circ}\right)$ & $19.20 \pm 3.21$ & $18.46 \pm 2.41$ & & $17.02 \pm 2.09$ & $\mathrm{AB}$ \\
\hline Absolute ROM $\left(^{\circ}\right)$ & $42.66 \pm 3.29$ & $40.15 \pm 3.73$ & A & $38.34 \pm 2.99$ & $\mathrm{AB}$ \\
\hline Relative ROM $\left(^{\circ}\right)$ & $13.00 \pm 6.45$ & $12.41 \pm 5.96$ & & $12.87 \pm 5.41$ & \\
\hline \multicolumn{6}{|l|}{ Coronal plane $(+=$ inversion/ - =eversion $)$} \\
\hline Angle at footstrike $\left(^{\circ}\right)$ & $3.32 \pm 2.86$ & $2.54 \pm 3.07$ & & $1.46 \pm 2.55$ & $\mathrm{~A}$ \\
\hline Angle at toe-off $\left(^{\circ}\right)$ & $0.02 \pm 3.41$ & $-1.06 \pm 3.59$ & & $-1.24 \pm 3.05$ & $\mathrm{~A}$ \\
\hline Peak Inversion $\left(^{\circ}\right)$ & $3.87 \pm 2.79$ & $3.16 \pm 3.07$ & & $1.92 \pm 2.74$ & A \\
\hline Peak Eversion $\left({ }^{\circ}\right)$ & $-9.78 \pm 3.70$ & $-10.28 \pm 3.78$ & & $-8.80 \pm 3.74$ & $\mathrm{~B}$ \\
\hline Absolute ROM $\left(^{\circ}\right)$ & $13.64 \pm 3.23$ & $13.44 \pm 3.20$ & & $10.72 \pm 2.30$ & $\mathrm{AB}$ \\
\hline Relative ROM $\left(^{\circ}\right)$ & $13.10 \pm 3.94$ & $12.82 \pm 3.69$ & & $10.26 \pm 2.87$ & $\mathrm{AB}$ \\
\hline \multicolumn{6}{|c|}{ Transverse plane $(+=$ external/ - =internal $)$} \\
\hline Angle at footstrike $\left(^{\circ}\right)$ & $-1.15 \pm 2.10$ & $-0.56 \pm 2.66$ & & $-0.43 \pm 2.91$ & \\
\hline Angle at toe-off $\left(^{\circ}\right)$ & $5.06 \pm 3.87$ & $5.61 \pm 3.95$ & & $4.87 \pm 4.42$ & \\
\hline Peak Internal rotation $\left({ }^{\circ}\right)$ & $-8.82 \pm 4.44$ & $-8.33 \pm 4.53$ & & $-8.06 \pm 4.38$ & \\
\hline Absolute ROM $\left(^{\circ}\right)$ & $13.94 \pm 4.18$ & $14.02 \pm 4.02$ & & $13.12 \pm 3.43$ & \\
\hline Relative ROM $\left(^{\circ}\right)$ & $7.67 \pm 3.13$ & $7.78 \pm 2.83$ & & 7.632 .47 & \\
\hline
\end{tabular}

400 Note. $A=$ significant difference from WITHOUT condition, $\mathrm{B}=$ Significant difference from PROTECTOR

401 condition.

402

403 
Table 2. Kinematic data (means and stand deviations) for the Knee obtained during stance

406 phase of the running gait.

\begin{tabular}{|c|c|c|c|}
\hline & WITHOUT & PROTECTOR & $\overline{\text { BRACE }}$ \\
\hline \multicolumn{4}{|c|}{ Sagittal plane (+ = Flexion / - = Extension) } \\
\hline Angle at footstrike $\left(^{\circ}\right)$ & $11.99 \pm 4.35$ & $12.58 \pm 4.36$ & $12.83 \pm 3.81$ \\
\hline Angle at toe-off $\left(^{\circ}\right)$ & $12.49 \pm 4.62$ & $14.32 \pm 6.05$ & $14.12 \pm 5.50$ \\
\hline Peak Flexion $\left(^{\circ}\right)$ & $40.09 \pm 3.97$ & $40.55 \pm 3.70$ & $40.17 \pm 3.98$ \\
\hline Absolute ROM $\left(^{\circ}\right)$ & $30.56 \pm 4.43$ & $30.31 \pm 3.42$ & $29.54 \pm 3.54$ \\
\hline Relative ROM $\left(^{\circ}\right)$ & $28.10 \pm 4.96$ & $27.97 \pm 4.96$ & $27.34 \pm 4.08$ \\
\hline \multicolumn{4}{|c|}{ Coronal plane (+ = Adduction $/-=$ Abduction) } \\
\hline Angle at footstrike $\left(^{\circ}\right)$ & $0.14 \pm 4.18$ & $-0.6 \pm 4.24$ & $-0.43 \pm 4.50$ \\
\hline Angle at toe-off $\left(^{\circ}\right)$ & $-3.16 \pm 2.78$ & $-3.14 \pm 2.92$ & $-3.15 \pm 3.00$ \\
\hline Peak Adduction $\left(^{\circ}\right)$ & $2.92 \pm 4.66$ & $2.73 \pm 4.66$ & $2.56 \pm 4.38$ \\
\hline Absolute ROM $\left(^{\circ}\right)$ & $6.52 \pm 2.40$ & $6.65 \pm 2.30$ & $6.42 \pm 1.76$ \\
\hline Relative ROM $\left(^{\circ}\right)$ & $2.79 \pm 2.65$ & $2.79 \pm 2.76$ & $2.99 \pm 2.60$ \\
\hline \multicolumn{4}{|c|}{ Transverse plane (+ = Internal / - = External) } \\
\hline Angle at footstrike $\left(^{\circ}\right)$ & $-12.96 \pm 6.03$ & $-12.18 \pm 7.46$ & $-11.94 \pm 7.23$ \\
\hline Angle at toe-off $\left(^{\circ}\right)$ & $-8.37 \pm 4.39$ & $-7.52 \pm 4.98$ & $-7.17 \pm 5.00$ \\
\hline Peak Internal Rotation $\left(^{\circ}\right)$ & $0.20 \pm 6.72$ & $0.62 \pm 7.67$ & $0.31 \pm 7.22$ \\
\hline Absolute ROM $\left(^{\circ}\right)$ & $14.07 \pm 5.89$ & $13.84 \pm 6.32$ & $13.12 \pm 6.30$ \\
\hline Relative ROM $\left(^{\circ}\right)$ & $13.16 \pm 6.49$ & $12.25 \pm 6.90$ & $12.25 \pm 6.69$ \\
\hline
\end{tabular}

407 Note. $A=$ significant difference from WITHOUT condition, $B=$ Significant difference from PROTECTOR

408 condition.

409

410

411

412

413

414

415 
417 Table 3. Kinematic data (means and stand deviations) for the Hip obtained during stance

418 phase of the running gait.

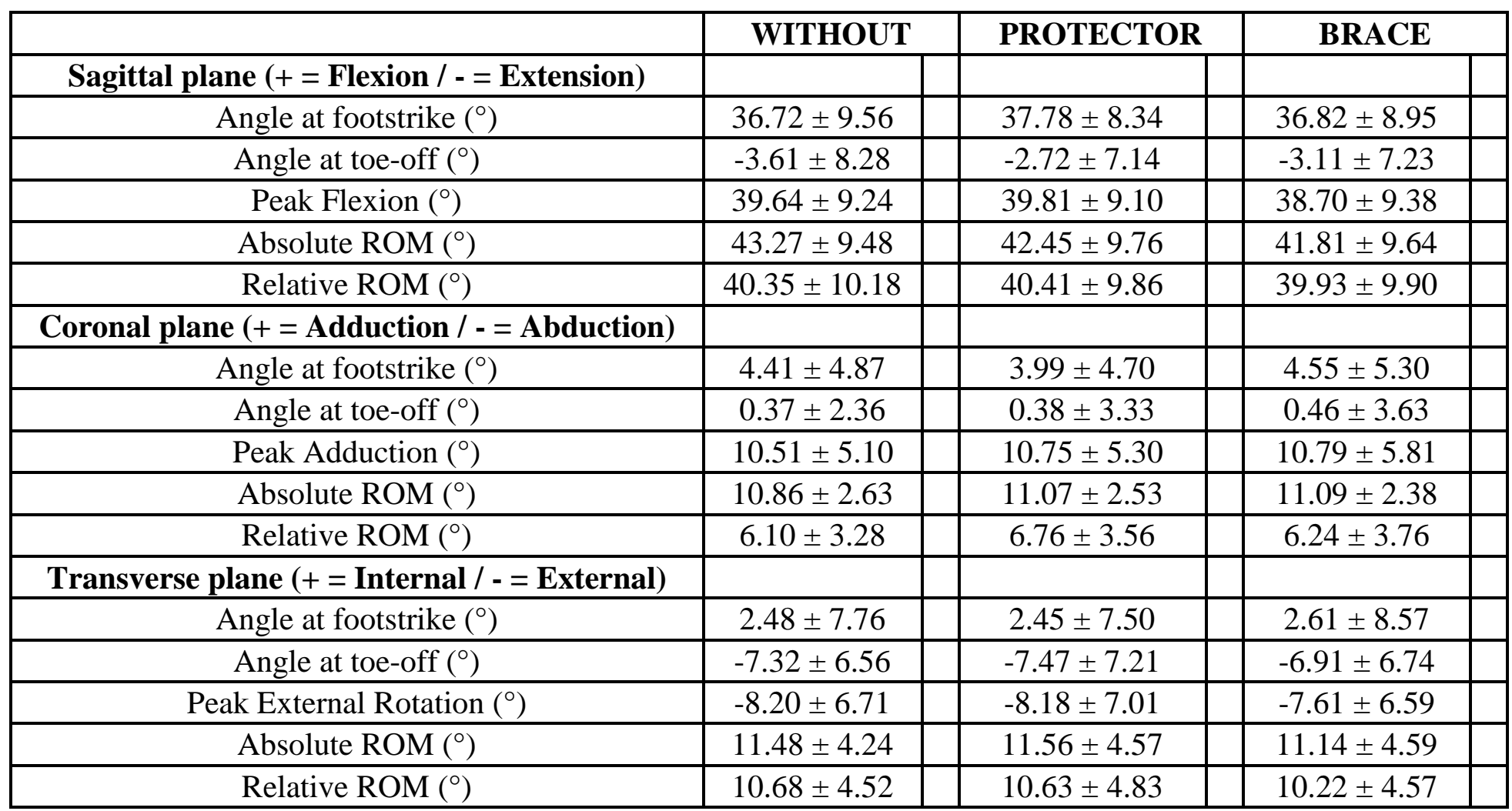

419 Note. $A=$ significant difference from WITHOUT condition, $B=$ Significant difference from PROTECTOR

420 condition.

421

422 
Dear Reviewers and Editor,

I have made further revisions based on your feedback and I hope that I have addressed all the concerns that you have. Below I have detailed the changes I have made and I have highlighted the changes in red on the revised version of the paper.

Editor: The referees have reviewed the revision of this interesting paper and both find it much improved. They both have minor concerns that need to be addressed in a second revision. Please make the changes in a red font and also provide a point by point response to the comments. The editor will review the revision.

Reviewer \#1: Thank you very much for the re-submission of the paper which in my opinion has improved a lot.

There are three general points before I write some more detailed comments:

1. Why is it so important to know if protectors restrict ankle movement? Please include in the introduction and discussion some answers to this question.

I have added a statement about why ankle protectors restricting movement might be important.

2. You present the kinematic data from the knee and hip but you don't give a reason in the introduction why you collect those data and also in the discussion section you don't write something about this.

I have added a statement explaining the inclusion of knee and hip data in the introduction and have added a section to the discussion too.

3. Be a bit more precise with your conclusion that the movement closely resembles that of an unbraced ankle: don't forget that in sagittal plane there are significant differences I have changed the conclusion so it is more precise and includes the differences found in the sagittal plane.

Abstract:

Lines 41-44: Adapt the conclusion

Adapted the conclusion to be more precise

Introduction:

Line 76: It's not really true to say that acute or chronic injuries can be prevented depending on the device. Please amend.

I have added the phrase "the risk of..." to this sentence

Discussion:

This section is the weakest section of the article. I am missing more discussion on implications of the changes kinematics on performance/injury... Also, I think you could be a bit more critical with your results: For example include a discussion on the accuracy of data especially when placing the markers on top of the devices. Your data have very large standard deviations - please also include this in the discussion or/and refer to the Effect size. As I said above, I am missing the discussion of knee and hip data.

I have added more information which I hope covers all the points above.

Line 210: Why is it imperative to understand the kinematics? What influence has a restriction on performance/ injury?

I think the sentence I used was a poor choice so I have changed this so the paragraph reads better 
Line 213-214: Yes, there is no significant difference if you look at the parameters you have analysed, however, if you look at Figure $2 b$ - it looks like especially in this plane there is a big difference. Is this the graph of one person or the mean of all?

It is the mean of all participants. I have just spotted that the ankle graphs have been mislabelled in the version I have sent in and should be PROTECTOR = dash, BRACE = black, WITHOUT = grey on that one. This is different to the labelling of the knee and hip so I have redone the ankle graphs so the lines match the same style as the knee and hip and are now correctly labelled in the version I have sent in with this submission.

Line 225-229: again, what is the implication on function?

Added information to this paragraph to discuss implication

Line 241: this is not true for sagittal plane.

Lines 245-247: Why is this important? What are the implications for practice?

Added sentences to answer this.

Reviewer \#2: This version of the manuscript is much improved, and I appreciate the authors incorporating the reviewers' comments into the revised manuscript. I have some further suggestions to improve the current version.

The abstract refers to both running and jogging. I believe jogging is probably the better word choice here, and throughout the manuscript in any reference to applicability, given that the speed is $3.4 \mathrm{~m} / \mathrm{s}$, and this would be a relatively slow speed during a soccer match. I feel most would associate the term "running" during soccer with more of a sprint speed. You have generally used jogging throughout the manuscript, which I agree with. I think the few mentions of "running" within the paper are fine as-is, but the tables could be updated to use the term "jogging" for consistency.

Line 105. It should be specified that the $22 \mathrm{~m}$ distance is part of a runway. It should also be stated what material it is (i.e., rubber track ,concrete, artificial turf, etc.).

Line 117. Data are plural, thus data "were" recorded Changed to "were recorded"

Line 162-163. While I realize you mentioned the means were computed in the previous paragraph, please state "The means of the five trials for each of the three test conditions were compared..." Added "The means of the five trials for each of..." to the sentence

Line 169. No need to report height, body mass, and BMI beyond one decimal point. Changed to 1 decimal place

Line 220-221. Awkwardly worded, run-on sentence

I am sorry I did not mention this previously, but it should also be mentioned that the rigid/semi-rigid materials used for both the ankle protector and the ankle brace do not necessarily represent actual movement at the ankle. Markers placed on the skin are subject to some movement, which is a limitation in 3D motion analysis, but markers placed on the surfaces of the protector/brace may differ from the true location of the malleolus during dynamic movements, and this may differ 
between the brace and protector. The authors have done a good job describing how they did the best job possible in ensuring proper static position, but the possibility of ankle markers having some error during movement, and the error differing between conditions, must be included in the limitations.

I appreciate that this is an issue however the markers affixed to the malleoli where not used to track the dynamic movement only for defining the segment in the static. The shank was tracked using a rigid plastic mount located on the shank itself and the foot was tracked using the 1st and 5th metatarsal heads and the calcaneus. This allowed me to compute the ankle movement without using the malleoli markers in the dynamic trials.

I appreciate the inclusion of the other various limitations for the final paragraph. 

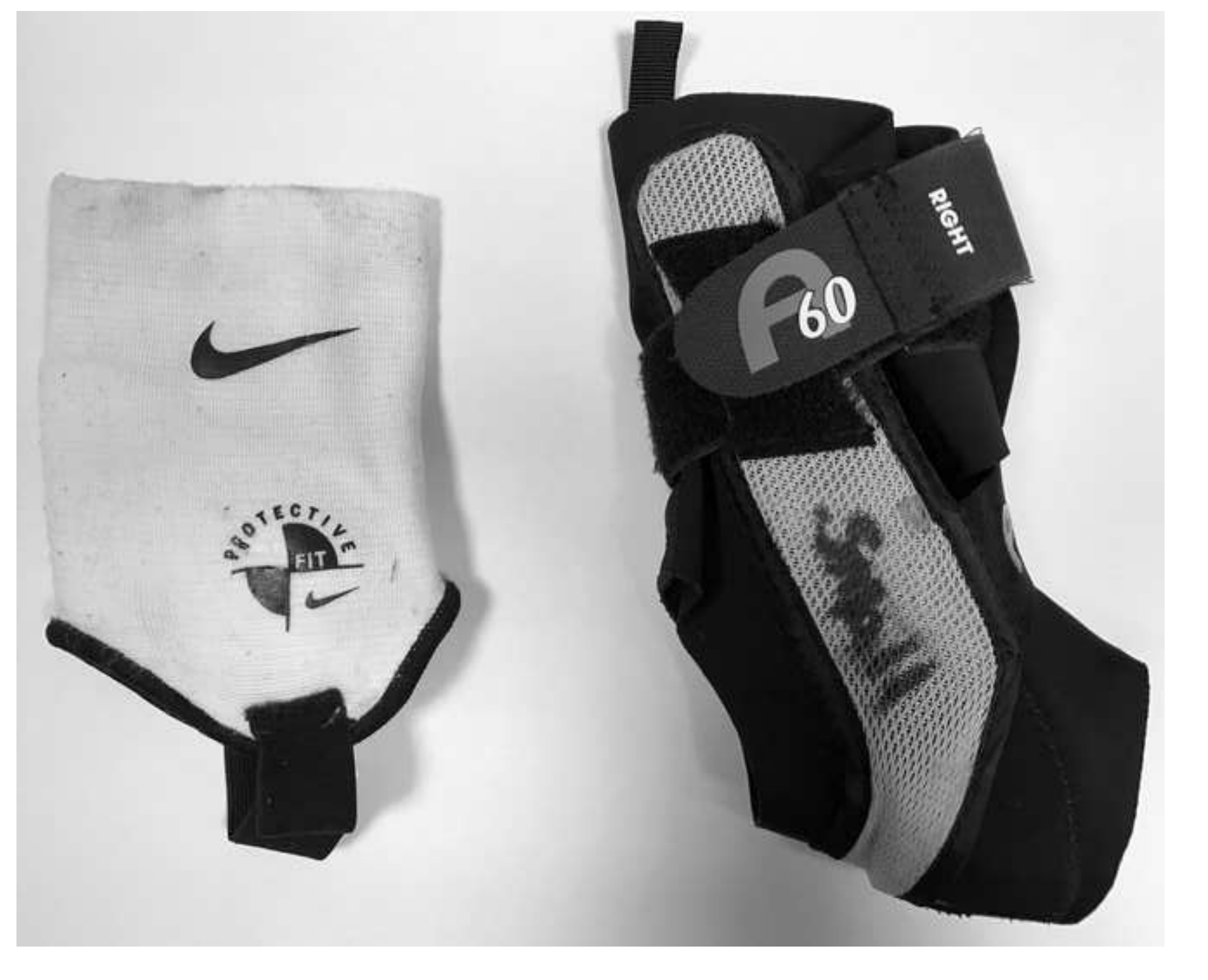

Figure 1- Photos

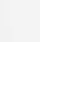



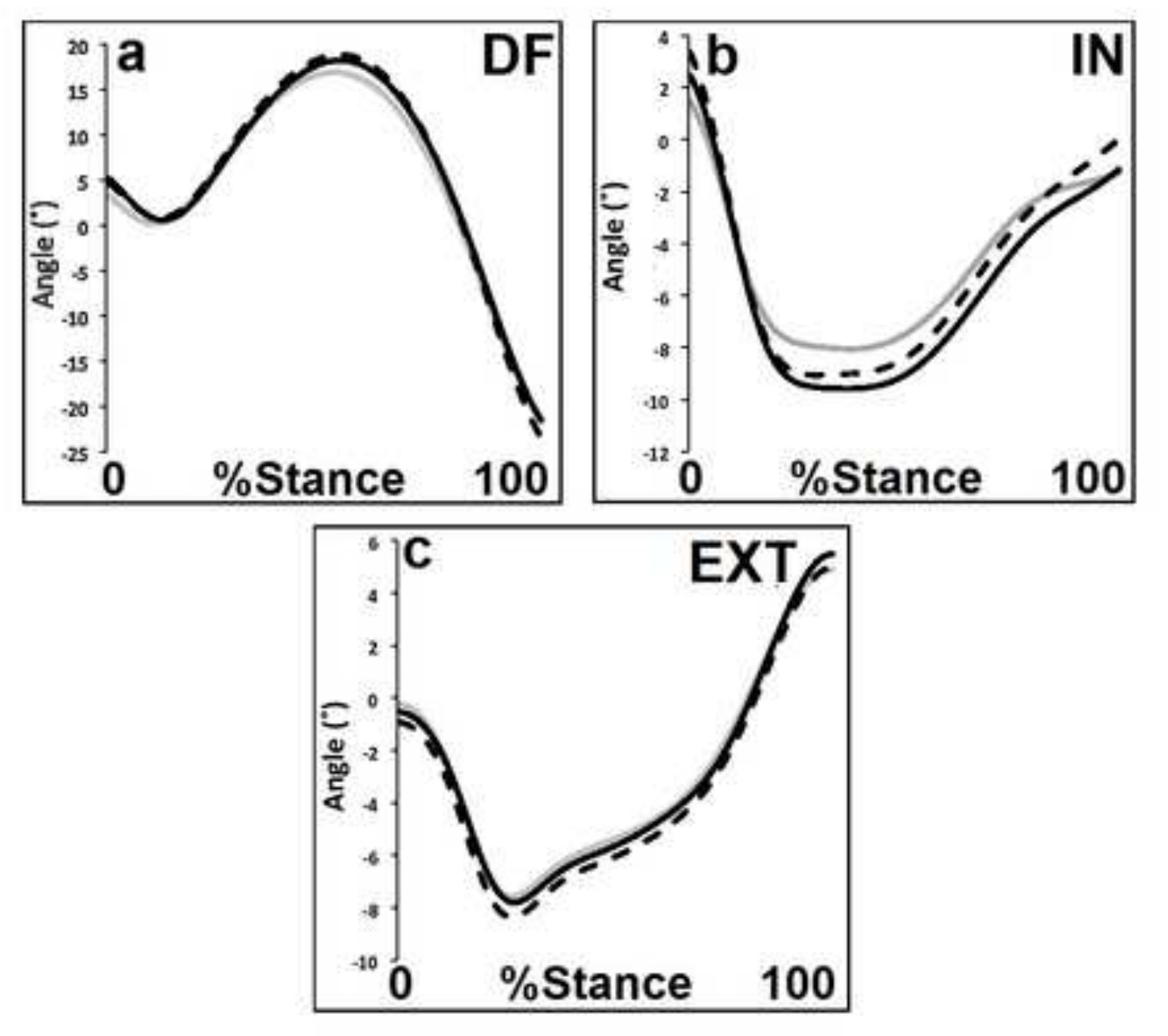

Figure 2- Ankle

\%
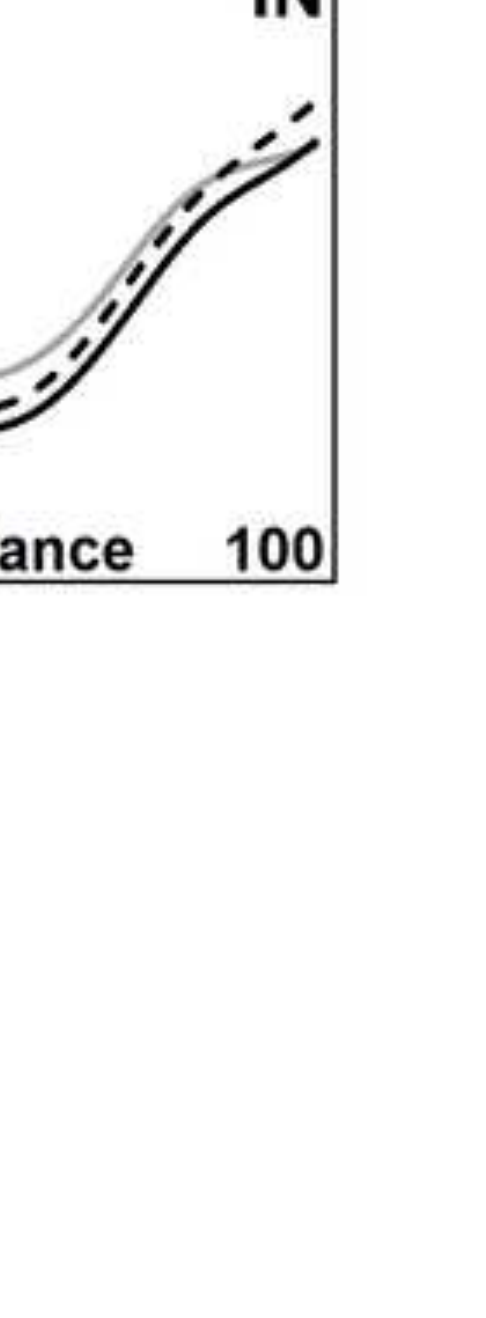

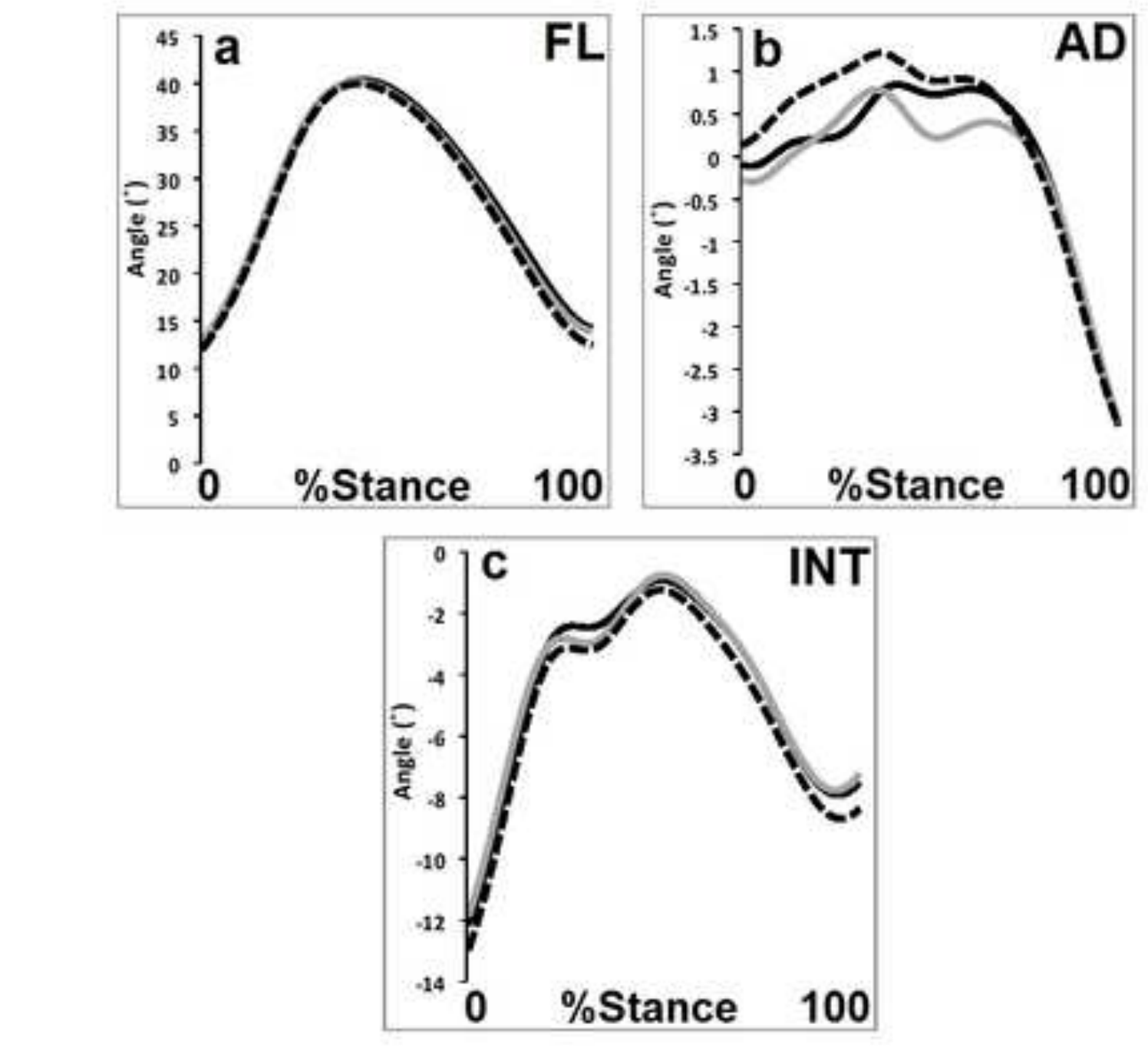

Figure 3- Knee

Figure 3-Knee

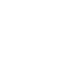



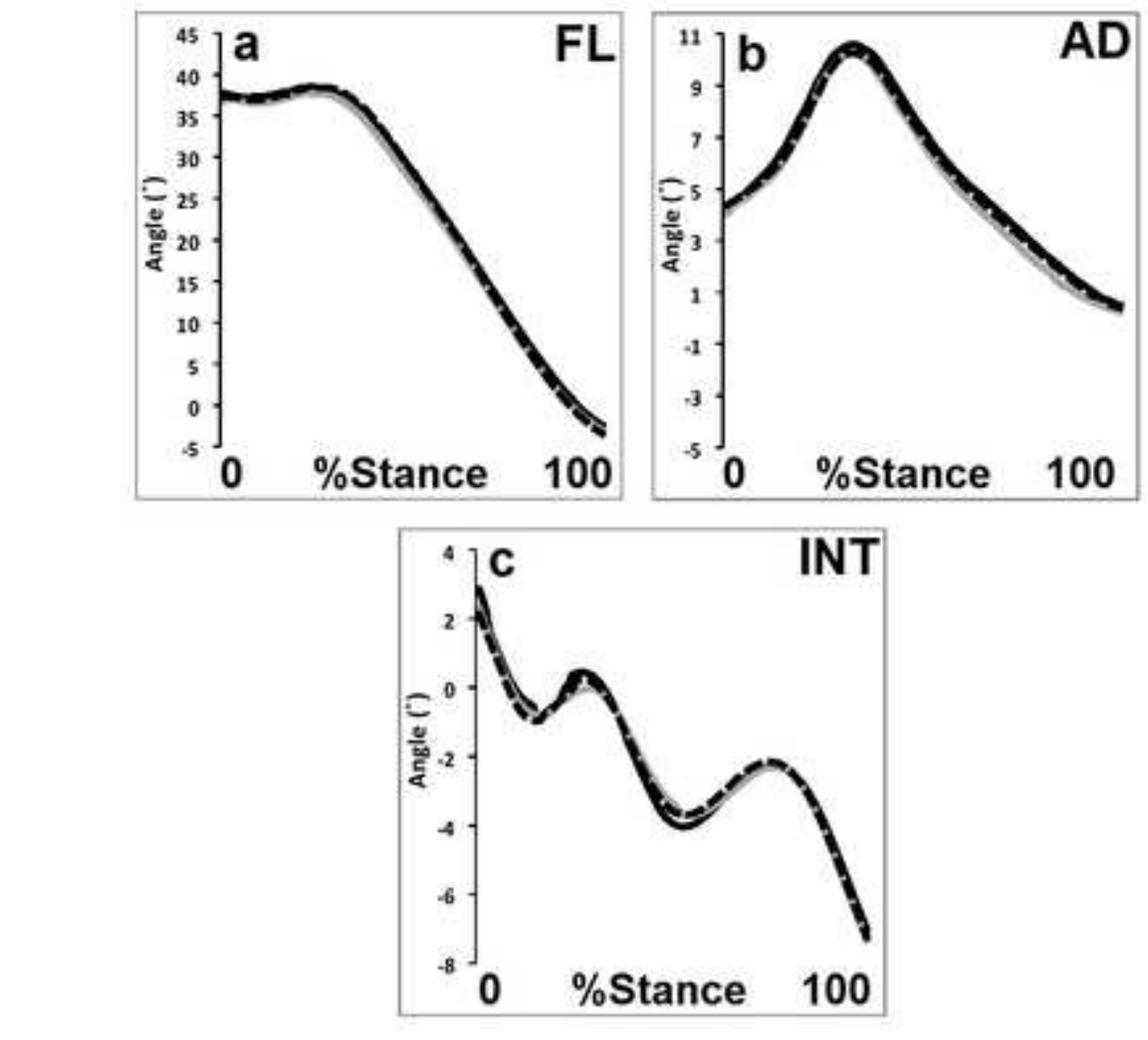

Figure 4- Hip

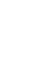

